\title{
Friction and wear behavior of carbon fiber reinforced lithium aluminosilicate composites sliding against GCr15 steel
}

\author{
Haibao MA ${ }^{1}$, Xin WU ${ }^{1}$, Long XIA ${ }^{1, *}$, Longnan HUANG ${ }^{1}$, Li XIONG ${ }^{1}$, Hua YANG ${ }^{2}$, Bo ZHONG ${ }^{1}$, Tao ZHANG ${ }^{1}$, \\ Zhiwei YANG ${ }^{1}$, Feng GAO ${ }^{1}$, Guangwu WEN ${ }^{3}$ \\ ${ }^{1}$ School of Materials Science and Engineering, Harbin Institute of Technology at Weihai, Weihai 264209, China \\ ${ }^{2}$ School of Science, Lanzhou University of Technology, Lanzhou 730050, China \\ ${ }^{3}$ School of Materials Science and Engineering, Shandong University of Technology, Zibo 255000, China \\ Received: 06 January 2019 / Revised: 18 June 2019 / Accepted: 11 August 2019 \\ (C) The author(s) 2019.
}

\begin{abstract}
Carbon fibers reinforced lithium aluminosilicate matrix composites $\left(\mathrm{C}_{\mathrm{f}} / \mathrm{LAS}\right)$ were prepared by slurry infiltration combined with a hot press procedure. The friction, wear behavior, and wear mechanisms of $\mathrm{C}_{\mathrm{f}} / \mathrm{LAS}$ composites under dry sliding conditions were investigated. The results show that the coefficient of friction (COF) initially increased with the increase in carbon fiber content, and reached the maximum value of 0.20 for the $33 \% \mathrm{C}_{\mathrm{f}} / \mathrm{LAS}$ composite. The COF increased sharply with increasing sample temperature from RT to $300{ }^{\circ} \mathrm{C}$. The COF remained stable in the temperature range of $300-500{ }^{\circ} \mathrm{C}$. The two wear mechanisms of LAS glassceramics are fatigue wear and abrasive wear. The $\mathrm{C}_{\mathrm{f}} / \mathrm{LAS}$ composites demonstrate slight spalling and shallow scratches. These results show that carbon fibers improve the mechanical properties and wear resistance of $\mathrm{C}_{\mathrm{f}} /$ LAS composites.
\end{abstract}

Keywords: unlubricated friction; ceramics composites; carbon fiber materials; long fibers; wear mechanisms

\section{Introduction}

The rapid development of mechanical engineering has led to the widespread use of gear transmission systems in various fields such as the textile industry, automobile industry, and aviation industry [1-3]. But these conventional gears have difficulty in meeting stricter stability, accuracy, and safety standards due to the nature of certain metals and alloys. For example, the heat released by wear could increase the temperature of the tooth mesh area and adversely affect the dimensional stability and mesh conditions, and as well as the gear adhesive. The faster the machine runs, the greater the amount of heat generated, and the stronger effect on the gear adhesive.

Ceramic materials are ideal for a variety of wearresistant and structural applications due to their unique mechanical properties, such as high hardness, moderate fracture toughness, excellent high-temperature wear and corrosion resistance, and high chemical stability [4-7]. Over the past few decades, many studies have been carried out on lithium aluminosilicate (LAS) glassceramics, one of the most important glass-ceramic systems with ultra-low coefficient of thermal expansion and excellent electrical properties [8-16]. However, like other ceramic materials, LAS glass ceramics are fragile, which hinders their wide application; hence, strengthening LAS is important. The addition of fibers or whiskers to LAS glass-ceramic substrates to make fiber-reinforced composites has been proven to be very effective in improving toughness [17-21].

Carbon fiber $\left(\mathrm{C}_{\mathrm{f}}\right)$ has many positive characteristics, including high strength, low density, good lubricating properties, and excellent friction and wear properties.

* Corresponding author: Long XIA, E-mail: xialonghit@gmail.com 


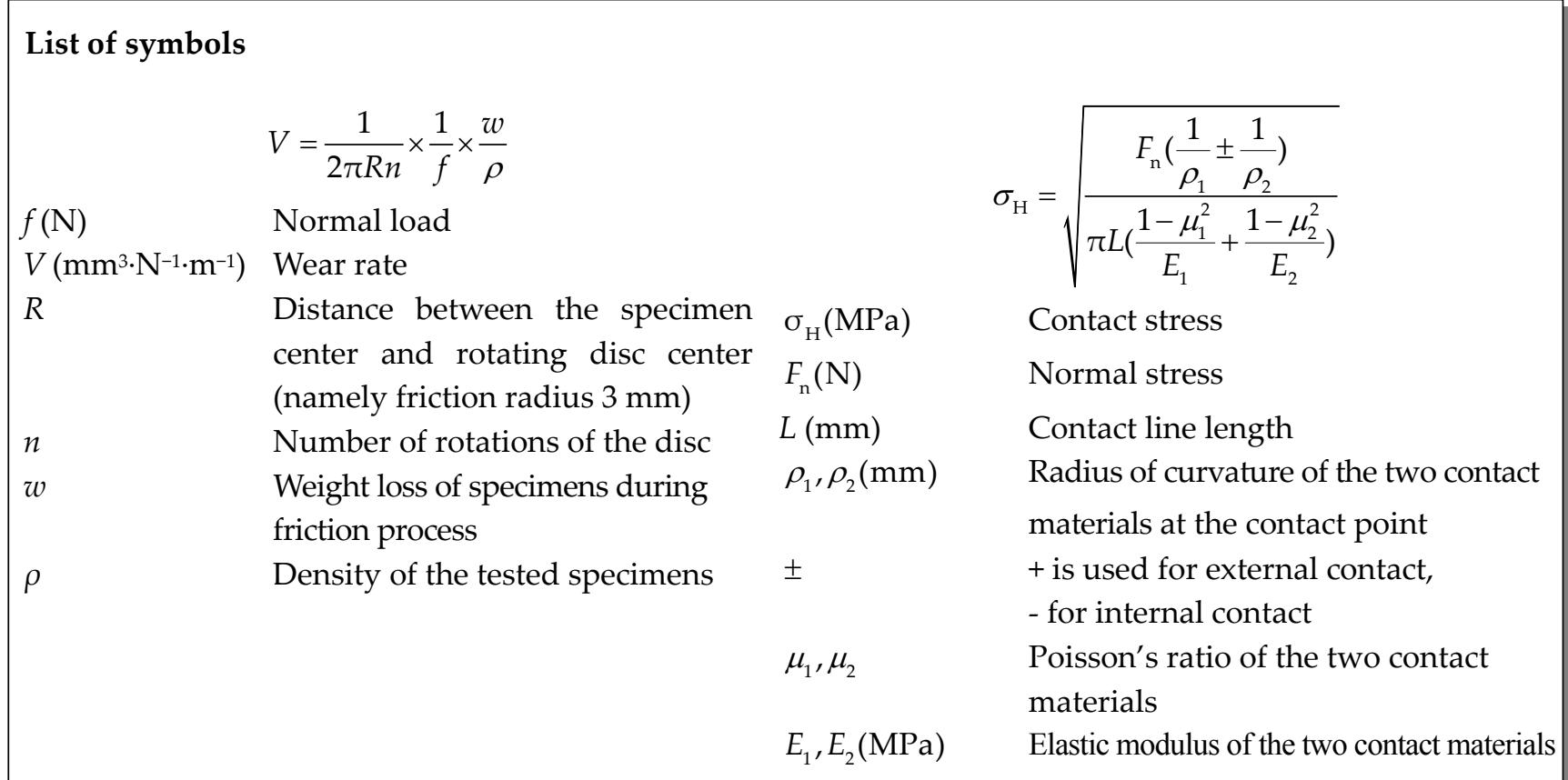

In particular, their axial thermal expansion coefficient is close to zero, which gives them similar thermal expansion properties as LAS glass-ceramics. Thus, $\mathrm{C}_{\mathrm{f}}$ and LAS can be fabricated into anti-wear composites with nearly zero thermal expansion [22-25]. $\mathrm{C}_{\mathrm{f}} / \mathrm{LAS}$ composite products can be used not only in precision gear transmissions and traditional machinery, but also in ultra-stable systems with high precision in high-tech systems.

Many researchers have reported that the solidlubrication effect of carbon/ceramic composites can improve wear-resistance properties to allow their use in tribological applications. Seghi et al. [26] reported that carbon fiber/C-BN composites with density of $1.55 \mathrm{~g} / \mathrm{cc}$ displayed a wear rate $50 \%$ lower than that of $\mathrm{C} / \mathrm{C}$ samples with densities of approximately 1.75-1.8 g/cc. Zhou et al. [27] found that carbon fiber/ C-SiC dual matrix composites exhibit stable and high COFs with low wear rate. Hyuga et al. [28] found that carbon fiber content of $5 \mathrm{vol} \%$ in silicon nitride was sufficient to maintain low COF during sliding tests under dry conditions.

To the best of our knowledge, there are few reports on the tribological properties of $\mathrm{C}_{\mathrm{f}} / \mathrm{LAS}$ composites, especially under dry conditions, where the COF and wear rate are much higher. In our previous work, LAS glass-ceramic matrix composites were fabricated by sol-gel process, after which continuous carbon fibers were infiltrated into the as-prepared slurry, followed by uniaxial hot pressing $[29,30]$. In this paper, we explore the friction and wear behavior of $\mathrm{C}_{\mathrm{f}} / \mathrm{LAS}$ composites with different carbon fiber content under different temperature conditions. Wear mechanisms of $\mathrm{C}_{\mathrm{f}} / \mathrm{LAS}$ composites are also proposed to determine the conditions for their potential applications.

\section{Materials and methods}

\subsection{Specimen preparation}

The polyacrylonitrile (PAN)-based carbon fibers used in this study have a diameter of 6-8 $\mu \mathrm{m}$, density of $1.76 \mathrm{~g} / \mathrm{cm}^{3}$, and tensile strength and modulus of 2,930 MPa and 200-230 GPa, respectively. LAS sol in the form of $\beta$-spodumene $\left(\mathrm{Li}_{2} \mathrm{O}-\mathrm{Al}_{2} \mathrm{O}_{3}-4 \mathrm{SiO}_{2}\right)$ was synthesized via sol-gel method by first mixing boehmite sol, silica sol, and lithium salt using deionized water as media. Experimental material details are listed in Table 1 . The slurry was prepared by mixing the binder and LAS sol through the ball milling approach. Ball milling was carried out for $2 \mathrm{~h}$ in a sealed agate mortar containing half the volume of agate balls. The prepreg was prepared by infiltrating the continuous carbon fiber into the as-prepared slurry, and then dried at 
Table 1 Experimental materials.

\begin{tabular}{ccc}
\hline Materials & Sources & Specification \\
\hline $\begin{array}{c}\text { Aluminum } \\
\text { nitrate }\end{array}$ & $\begin{array}{c}\text { Tianjin BASF Chemical } \\
\text { Co., Ltd. }\end{array}$ & Analytical purity \\
$\begin{array}{c}\text { Lithium } \\
\text { nitrate }\end{array}$ & $\begin{array}{c}\text { Shanghai Shanpu Chemical } \\
\text { Co., Ltd. }\end{array}$ & Analytical purity \\
Silicon gel & $\begin{array}{c}\text { Qingdao Yuminyuan Silicone } \\
\text { Reagent Factory }\end{array}$ & $\mathrm{SiO}_{2}(\mathrm{wt} \%)$ : \\
& Laiyang Economic and & \\
Ammonia & $\begin{array}{c}\text { Technological Development } \\
\text { Zone Fine Chemical Plant }\end{array}$ & Analytical purity $^{2}$ \\
& $\begin{array}{c}\text { Weihai Guangwei Composite } \\
\mathrm{C}_{\mathrm{f}}\end{array}$ & Materials Co., Ltd. \\
\hline
\end{tabular}

$100{ }^{\circ} \mathrm{C}$. The preparation process of the unidirectional $\mathrm{C}_{\mathrm{f}} / \mathrm{LAS}$ composite material is as follows. First, carbon fibers continuously passed through the slurry tank until a layer of slurry was suspended on the surface of the carbon fiber. Then, the carbon fiber with slurry was wrapped around the drum to form a unidirectional carbon fiber cloth impregnated with the slurry. Finally, the unidirectional carbon fiber ribbon was cut into a size of $40 \mathrm{~mm} \times 60 \mathrm{~mm}$, laminated, and placed in a graphite mold. The $\mathrm{C}_{\mathrm{f}} / \mathrm{LAS}$ composite was prepared by hot press sintering at $1,400{ }^{\circ} \mathrm{C}$ and $10 \mathrm{MPa}$ for $0.5 \mathrm{~h}$. There was no subsequent heat treatment. The carbon fiber content of $\mathrm{C}_{\mathrm{f}} / \mathrm{LAS}$ composites ranged from 0 to $45 \mathrm{vol} \%$, and the corresponding samples were denoted as LAS, $33 \% \mathrm{C}_{\mathrm{f}} / \mathrm{LAS}, 37 \% \mathrm{C}_{\mathrm{f}} / \mathrm{LAS}$, and $45 \% \mathrm{C}_{\mathrm{f}} / \mathrm{LAS}$. Figure 1 shows the fracture interface of the $\mathrm{C}_{\mathrm{f}} / \mathrm{LAS}$ composite. It can be seen that the carbon fibers are tightly connected to the matrix and relatively evenly distributed in the matrix.

\subsection{Testing and analysis}

Relative densities of the samples were measured with deionized water as immersion medium according to the Archimedes principle. The density was measured at room temperature, and the density of deionized water was $1 \mathrm{~g} / \mathrm{cm}^{3}$. The bending mechanical properties were measured by three-point-bending tests on $3 \mathrm{~mm} \times$ $4 \mathrm{~mm} \times 36 \mathrm{~mm}$ bars with a span of $30 \mathrm{~mm}$ and crosshead speed of $0.5 \mathrm{~mm} / \mathrm{min}$ using an electronic control system.

Single-edge notched-beam test was conducted to evaluate the fracture toughness with a crosshead of $0.05 \mathrm{~mm} \cdot \mathrm{min}^{-1}$ and a span of $20 \mathrm{~mm}$. The sample size was $2 \mathrm{~mm} \times 4 \mathrm{~mm} \times 20 \mathrm{~mm}$; the notch depth thickness was half that of sample thickness. The pre-notch was introduced by abrasive cutting with a $300 \mu \mathrm{m}$ thick diamond plate. The notch was made in the plane normal to the fiber layers. The phase and crystallite structures of the sample were measured by X-ray diffraction (XRD) with $\mathrm{Cu} \mathrm{K} \alpha$ radiation.

\subsection{Tribological test}

To avoid any other lubricating effect caused by ambient factors, the experiments were carried out under dry conditions with relative humidity of $25 \pm 5 \%$. The LAS and $\mathrm{C}_{\mathrm{f}} /$ LAS composites were machined into $30 \mathrm{~mm} \times 30 \mathrm{~mm} \times 3 \mathrm{~mm}$ plate specimens, and their friction behaviors were evaluated by ball-on-disk experiments at different temperatures against a polished commercial GCr15 steel ball with diameter of $5 \mathrm{~mm}$ and hardness of HV750.

Friction and wear tests were carried out using a high-temperature friction and wear tester (HT-1000, Lanzhou Keshen), as shown in Fig. 2. The disc temperature was controlled by a heating device. Sliding conditions were set as sliding diameter of $6 \mathrm{~mm}$, sliding speed of $0.18 \mathrm{~m} \cdot \mathrm{s}^{-1}$, applied force of $10 \mathrm{~N}$, and

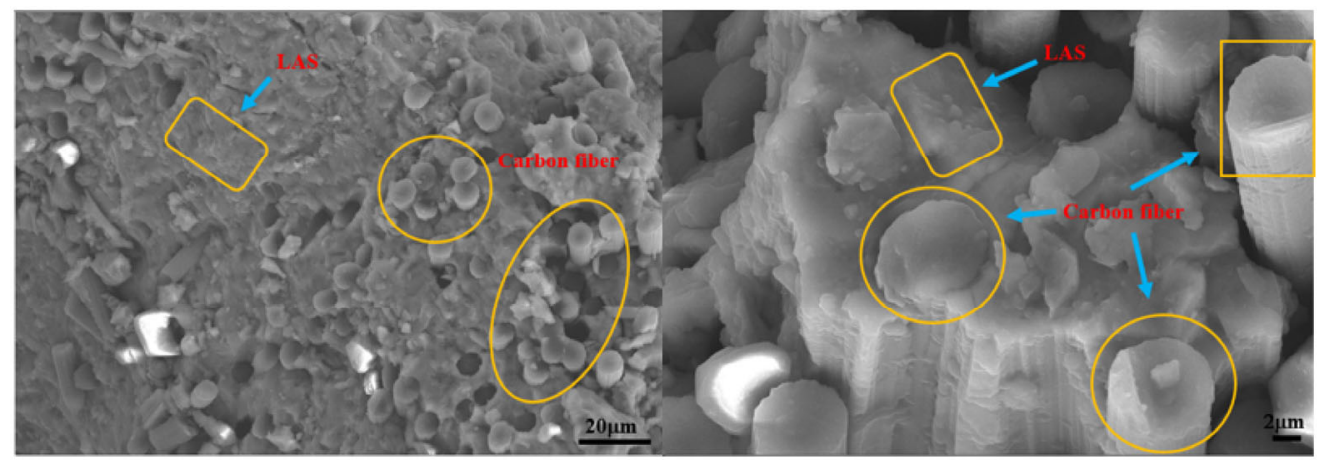

Fig. 1 Fracture interface of prepared $\mathrm{C}_{\mathrm{f}} / \mathrm{LAS}$ composite. 


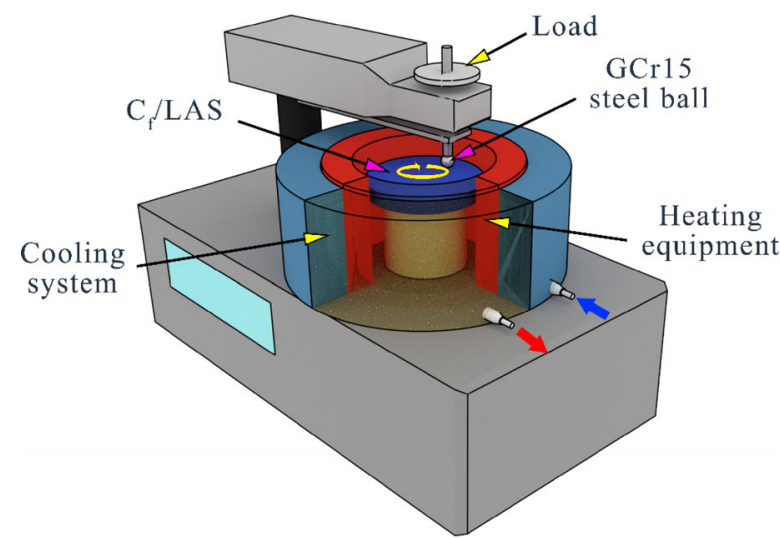

Fig. 2 Schematic of the experimental setup for the tribological test.

sliding distance of $5,000 \mathrm{~m}$. The friction force was measured continuously during each test. Before the sliding wear tests, all the specimen surfaces were ground with an 800-mesh sand paper. Frictional forces were measured by a friction torque transducer and the data was transferred to a personal computer by a software system at room temperature, 200, 300, 400, and $500{ }^{\circ} \mathrm{C}$, respectively. The corresponding COFs were also recorded. The wear rates of the specimens were determined by a balance that measured the weight reduction of specimens with an accuracy of $0.0001 \mathrm{~g}$ before and after the wear test. Each COF and wear rate data was the average value of three tests. The wear rate was calculated according to the following equation:

$$
V=\frac{1}{2 \pi R n} \times \frac{1}{f} \times \frac{w}{\rho}
$$

where $V$ is the wear rate $\left(\mathrm{mm}^{3} \cdot \mathrm{N}^{-1} \cdot \mathrm{m}^{-1}\right), R$ is the distance between the specimen center and rotating disc center (i.e., friction radius of $3 \mathrm{~mm}$ ), $n$ is the number of rotations of the disc, $f$ is the normal load $(\mathrm{N}), w$ is the weight loss of specimens during friction process, and $\rho$ is the density of the tested specimens. Hertz stress was calculated by the formula:

$$
\sigma_{\mathrm{H}}=\sqrt{\frac{F_{\mathrm{n}}\left(\frac{1}{\rho_{1}} \pm \frac{1}{\rho_{2}}\right)}{\pi L\left(\frac{1-\mu_{1}^{2}}{E_{1}}+\frac{1-\mu_{2}^{2}}{E_{2}}\right)}}
$$

where $\sigma_{\mathrm{H}}$ is the contact stress (MPa), $F_{\mathrm{n}}$ is the normal stress $(\mathrm{N}), L$ is the contact line length $(\mathrm{mm}), \rho_{1}$ and $\rho_{2}$ are the radius of curvature $(\mathrm{mm})$ of two contact materials at the contact point, + denotes external contact, - denotes internal contact, $\mu_{1}$ and $\mu_{2}$ are the Poisson's ratio of the two contact materials, and $E_{1}$ and $E_{2}$ are the elastic modulus (MPa) of the two contact materials. According to existing experimental data, the initial value of the Hertz stress of the material can be estimated as $532 \mathrm{MPa}$. Wear tests with the same experimental parameters were repeated at least three times, and the $\mathrm{COF}$ and wear rate shown are the average values. The worn surface of block specimens was analyzed by scanning electron microscopy (SEM) and energy dispersive X-ray spectroscopy (EDS).

\section{Results and discussion}

\subsection{Phase analysis and physical properties}

The XRD pattern in Fig. 3 shows that the precipitated crystalline phase is $\beta$-spodumene (JCPDS: 35-0797). Its main peak appears in the $25.5^{\circ}$ sample LAS, $33 \% \mathrm{C}_{\mathrm{f}} / \mathrm{LAS}, 37 \% \mathrm{C}_{\mathrm{f}} / \mathrm{LAS}$, and $45 \% \mathrm{C}_{\mathrm{f}} / \mathrm{LAS}$. The amorphous carbon diffraction peak can be seen in the XRD pattern, but it is not labeled because it is not related to the experiment.

Table 2 shows the relative density and coefficient of thermal expansion (CTE) of $\mathrm{C}_{\mathrm{f}} / \mathrm{LAS}$ composites as a function of carbon fiber content. The relative density and CTE of composite materials were experimentally

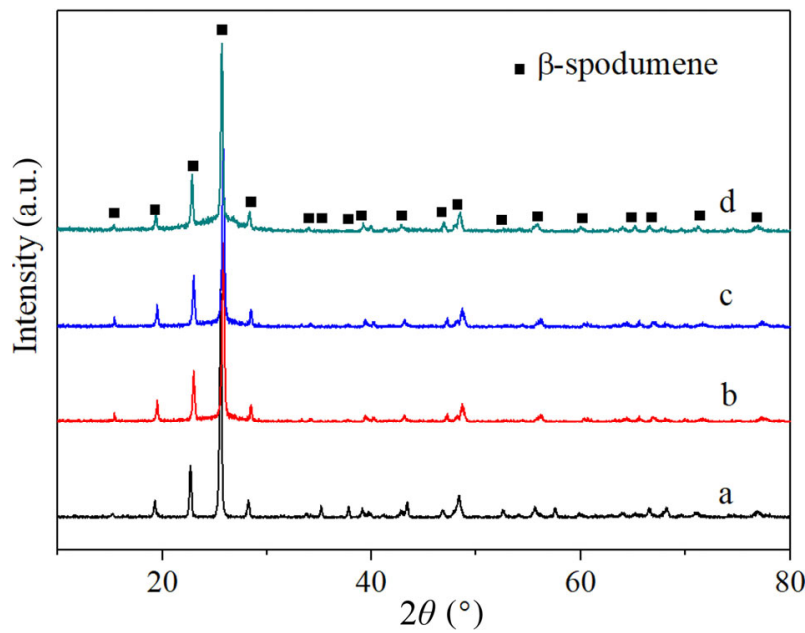

Fig. 3 XRD patterns of LAS and $\mathrm{C}_{\mathrm{f}} / \mathrm{LAS}$ composites with different carbon fiber content: (a) LAS glass-ceramics, (b) $33 \mathrm{vol} \%$ carbon fiber, (c) 37 vol\% carbon fiber, and (d) 45 vol\% carbon fiber. 
Table 2 Relative density and coefficient of thermal expansion of $\mathrm{C}_{\mathrm{f}} / \mathrm{LAS}$ composites with different carbon fiber content.

\begin{tabular}{ccc}
\hline $\begin{array}{c}\text { Carbon fiber } \\
\text { content }(\%)\end{array}$ & $\begin{array}{c}\text { Relative } \\
\text { density }(\%)\end{array}$ & $\begin{array}{c}\text { Coefficient of thermal } \\
\text { expansion }\left(10^{-6} \cdot \mathrm{K}^{-1}\right)\end{array}$ \\
\hline 0 & 97.7 & -0.02 \\
33 & 96.7 & 0.71 \\
37 & 95.8 & 0.62 \\
45 & 94.9 & 1.56 \\
\hline
\end{tabular}

measured. Carbon fibers with low CTE yield composites with high thermal stability. The LAS glassceramics specimen showed high relative density (97.7\%), or approximately $96.7 \%, 95.8 \%$, and $94.9 \%$ for composites with $33 \%, 37 \%$, and $45 \%$ carbon fiber, respectively. The increase in carbon fiber content leads to an obvious increase in the porosity of $\mathrm{C}_{\mathrm{f}} / \mathrm{LAS}$ composites. In this LAS glass-ceramic system, a glass phase along with the $\beta$-spodumene phase formed during the heat treatment process. The carbon fibers in $\mathrm{C}_{\mathrm{f}} / \mathrm{LAS}$ composites hindered the viscous flow of the glass phase during the hot pressing process, which increased the apparent porosity.

The hardness of $C_{f} /$ LAS composites is shown in Table 3. It can be seen that as the fiber content increased, the hardness of composites decreased due to the reduced continuity of composites, which results from the presence of fibers and the increase of porosity.

\subsection{Mechanical properties}

The physical and mechanical properties of friction materials are closely related to their friction and wear properties. The mechanical properties of $\mathrm{C}_{\mathrm{f}} / \mathrm{LAS}$ composites with different carbon fiber content are shown in Fig. 4. Both the flexural strength and fracture toughness rose with increasing carbon fiber content from 0 to $37 \%$. The maximum flexural strength and fracture toughness occurred in $37 \% \mathrm{C}_{\mathrm{f}} / \mathrm{LAS}$ composites, reaching $640 \pm 22 \mathrm{MPa}$ and $19.9 \pm 1.8 \mathrm{MPa} \cdot \mathrm{m}^{1 / 2}$,

Table 3 Hardness measurement.

\begin{tabular}{ccccc}
\hline $\begin{array}{c}\text { Carbon fiber } \\
\text { content }\end{array}$ & 1(HV) & 2(HV) & 3(HV) & $\begin{array}{c}\text { Average } \\
\text { value (HV) }\end{array}$ \\
\hline $0 \%$ & 650.7 & 651.3 & 650.7 & 650.8 \\
$33 \%$ & 276.8 & 277.3 & 279.3 & 277.8 \\
$37 \%$ & 243.2 & 244.6 & 243.9 & 243.9 \\
$45 \%$ & 156.4 & 157.1 & 156.9 & 156.8 \\
\hline
\end{tabular}

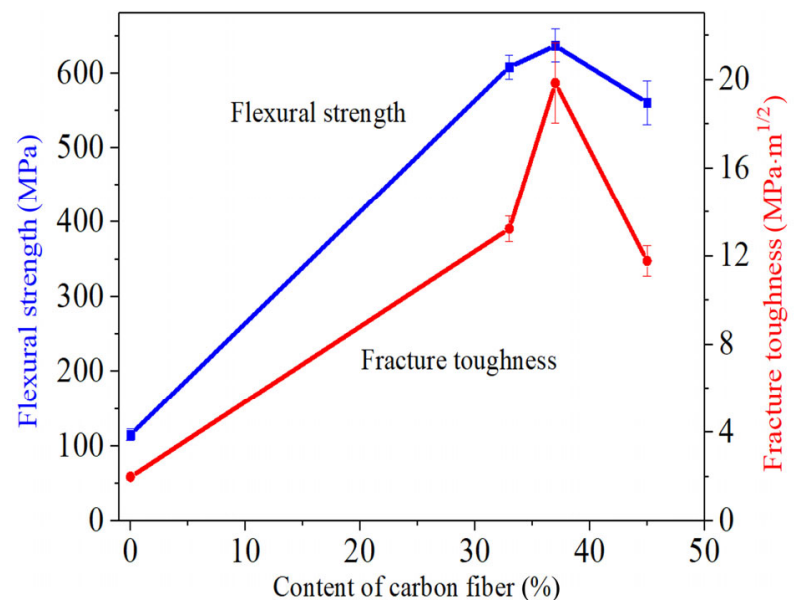

Fig. 4 Mechanical properties of $\mathrm{C}_{\mathrm{f}} / \mathrm{LAS}$ composites with different carbon fiber content.

respectively. With further increase in carbon fiber content, the strength and fracture toughness decreased.

\subsection{Tribological behaviors}

The effect of carbon fiber addition on the COF and the wear rate of specimens with different carbon fiber content are shown in Fig. 5. It can be seen that the carbon fiber content has a significant effect on $\mathrm{COF}$ and wear rate. The COF initially increased with the increase in carbon fiber content, and reached the maximum value 0.20 for $33 \% \mathrm{C}_{\mathrm{f}} / \mathrm{LAS}$ composites. The COF then decreased when the carbon fiber content was further increased. As seen in Fig. 5, the wear rate was significantly influenced by carbon fiber content. With increasing carbon fiber content, the wear rate rapidly decreased, followed by a slight increase, demonstrating an opposite trend compared with the COF.

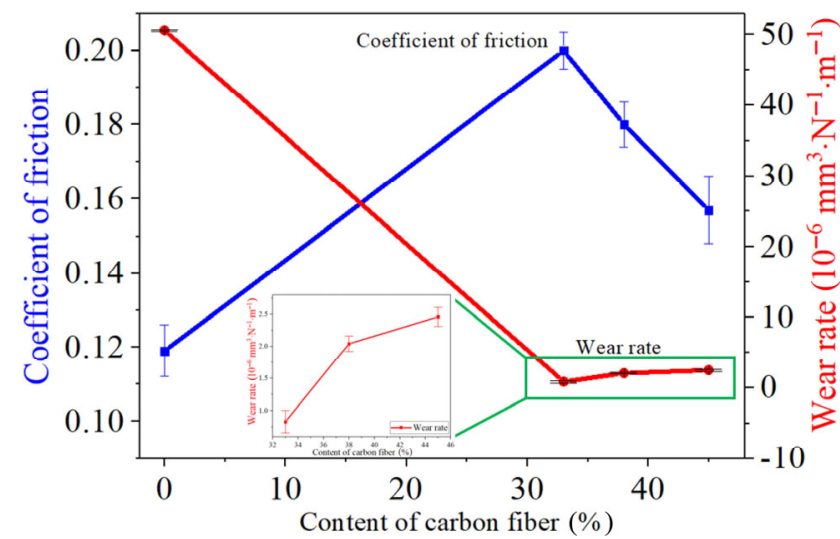

Fig. $5 \mathrm{COF}$ and wear rate of LAS and $\mathrm{C}_{\mathrm{f}} / \mathrm{LAS}$ composites with different carbon fiber content. 
The worn surfaces of LAS glass-ceramics and $\mathrm{C}_{\mathrm{f}} / \mathrm{LAS}$ composites with different carbon fiber content are shown in Fig. 6. As seen in Fig. 6(a), the worn surface of LAS glass-ceramics shows coarse characteristics along with some particles on the wear tracks; small cracks and chips were also observed. According to the morphology of wear damage, the wear type of LAS glass-ceramics against GCr15 steel could be attributed to a combination of fatigue wear and abrasive wear. In addition, LAS glass-ceramic particles spalled from the LAS matrix due to their low strength and brittle properties. The resulting particles during the frictional cycles also changed the abrasive style from two-body to three-body abrasion.

Adding 33 vol\% carbon fiber into LAS glass-ceramics changed the wear track morphology significantly (Fig. 6(b)), and a smooth tribofilm appeared on the worn surface, as shown in Fig. 6(b). Some obvious chipping along with cracks became visible on the worn surface. As the carbon fiber content was further increased to $37 \%$, tribofilm with a small number of cracks formed on the friction track (Fig. 6(c)). The worn surface of the $37 \% \mathrm{C}_{\mathrm{f}} / \mathrm{LAS}$ composites exhibited ploughing grooves and local deformation at $10 \mathrm{~N}$. The hard protrusions on the rough surface of the GCr15 steel ball cause microcuts on the softer surface of $37 \% \mathrm{C}_{\mathrm{f}} / \mathrm{LAS}$ composites, resulting in the formation of plough grooves during the friction process. With the

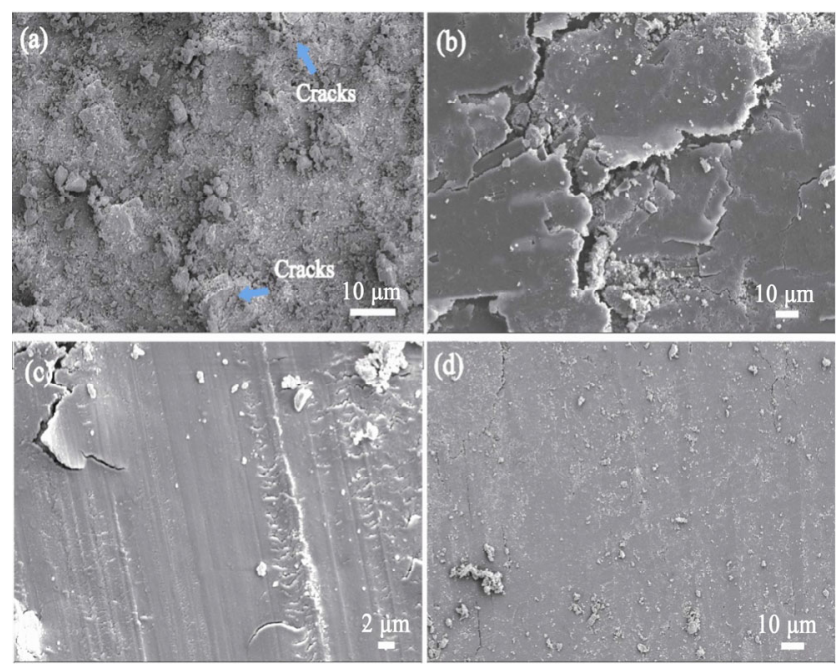

Fig. 6 Worn morphologies of LAS and $\mathrm{C}_{\mathrm{f}} /$ LAS composites with different carbon fiber content: (a) LAS glass-ceramics, (b) $33 \mathrm{vol} \%$ carbon fiber, (c) $37 \mathrm{vol} \%$ carbon fiber, and (d) $45 \mathrm{vol} \%$ carbon fiber.
$45 \% \mathrm{C}_{\mathrm{f}} / \mathrm{LAS}$ composites, the tribofilm became smoother and more coherent compared with other specimens (Fig. 6(d)). This smooth tribofilm decreased the COF between the sample and counterpart ball, which improved the wear resistance.

The line scanning of EDS is a powerful method to exhibit element distribution as a function of position change. Spectra were obtained at the border of the tribofilm and stripping surface to illustrate the concentration profile in this area (Fig. (7)). The lines canning results showed that the tribofilm of $37 \% \mathrm{C}_{\mathrm{f}} / \mathrm{LAS}$ contains a high concentration of oxygen along with a certain amount of Fe and C. Aluminum and silicon were not detected in this region. In contrast, the stripping surface mainly contained oxygen, silicon, and aluminum elements, corresponding to the chemical composition of $\mathrm{C}_{\mathrm{f}} / \mathrm{LAS}$ composites. When the material rubs against an abrasive material, the surface of the material loses its mass and falls off to form a powder. The powder mixes with and adheres to the abrasive material together; hence, the counter body material is detected.

The embedded carbon fibers from unpolished (ground only) surface were exposed and spread out on the wear track during reciprocating movements. The detached carbon fibers that rolled between the ball and composite surface were ground under the friction force. The carbon fibers were sufficient to contain a large number of graphite microcrystallites under dry conditions [30], which could be exfoliated

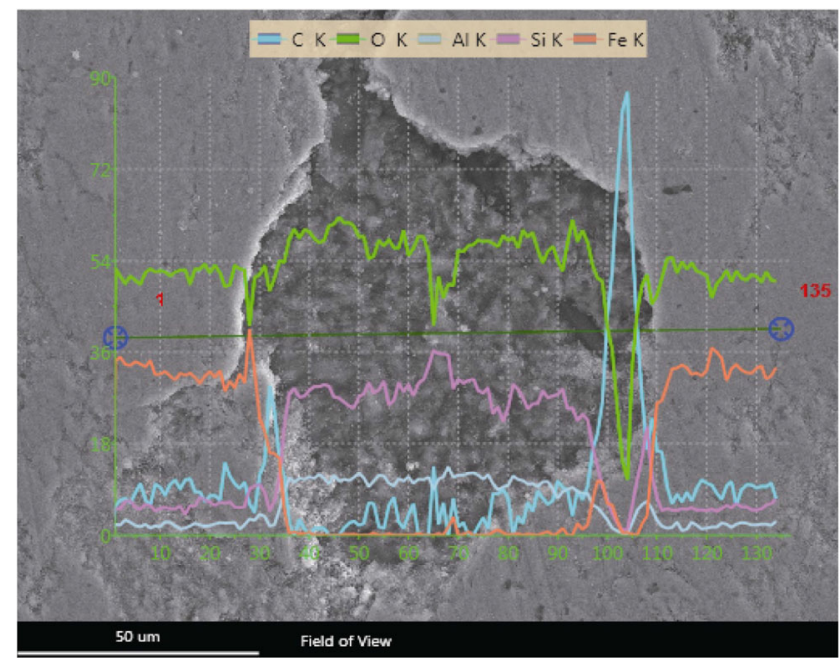

Fig. 7 EDS analysis of the worn surface of $37 \% \mathrm{C}_{\mathrm{f}} / \mathrm{LAS}$ composites. 
to form tribofilm. Thus, the increase in carbon fiber content is conducive to the formation of coherent tribofilm [31], which facilitates the improvement of the wear resistance of $\mathrm{C}_{\mathrm{f}} / \mathrm{LAS}$ composites.

The effects of temperature on COF and wear rate of $37 \% \mathrm{C}_{\mathrm{f}} / \mathrm{LAS}$ composites are shown in Fig. 8. The $37 \% \mathrm{C}_{\mathrm{f}} / \mathrm{LAS}$ composites were chosen as the focus of the study due to their excellent mechanical properties. The COF increased sharply with the increase in sample temperature. The COF of the $37 \% \mathrm{C}_{\mathrm{f}} / \mathrm{LAS}$ composites remained stable over the temperature range of 300 and $500{ }^{\circ} \mathrm{C}$, but the wear rate monotonically increased with increasing temperature. There were two wear modes in the friction process in the experiment: sliding wear and adhesive wear. As the temperature changed, the proportion of the two wear modes in the total wear process continuously changed. When the temperature was between 300 and $500{ }^{\circ} \mathrm{C}$, adhesive wear dominates. Thus, the COF is almost the same. However, compared with LAS glass-ceramics, the wear rate of composites containing carbon fiber was significantly reduced.

Figure 9 shows the worn morphologies of the $37 \% \mathrm{C}_{\mathrm{f}} /$ LAS composites at different sample temperatures. At $200{ }^{\circ} \mathrm{C}$, the worn surface of $37 \% \mathrm{C}_{\mathrm{f}} / \mathrm{LAS}$ composites presents a large area with spalling. The increase in sample temperature led to the formation of different worn surface morphologies. The worn surface of $37 \% \mathrm{C}_{\mathrm{f}} / \mathrm{LAS}$ composites friction tested at $300{ }^{\circ} \mathrm{C}$ demonstrated discontinuous characteristics. This rough surface had high COF. When the temperature

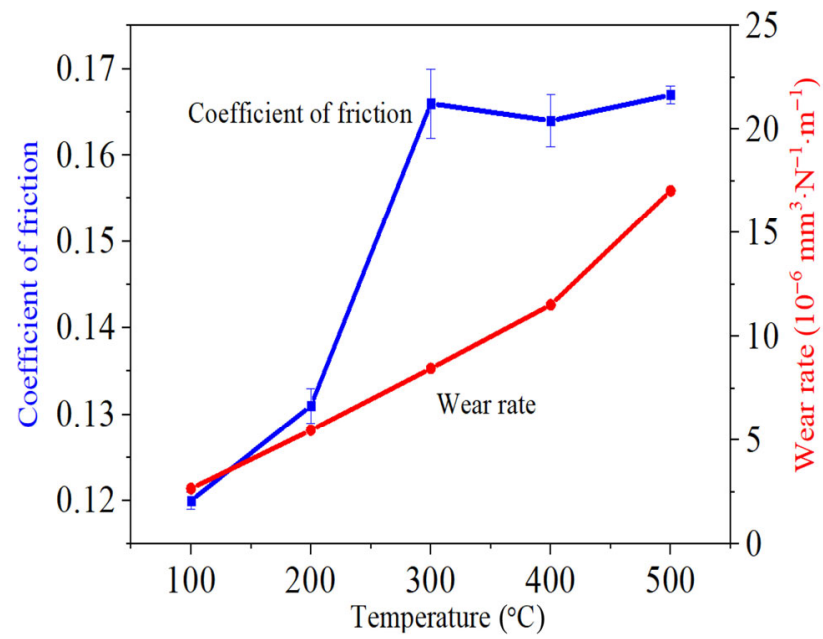

Fig. $8 \mathrm{COF}$ and wear rate of LAS and $\mathrm{C}_{\mathrm{f}} / \mathrm{LAS}$ composites at different temperature.

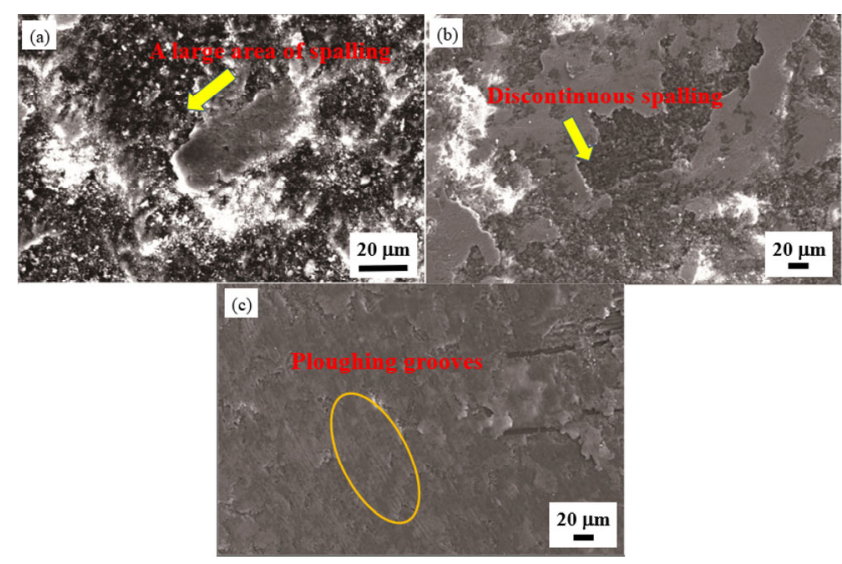

Fig. 9 Worn morphologies of $37 \% \mathrm{C}_{\mathrm{f}} / \mathrm{LAS}$ composites at different temperature: (a) $200{ }^{\circ} \mathrm{C}$, (b) $300{ }^{\circ} \mathrm{C}$, and (c) $400{ }^{\circ} \mathrm{C}$.

increased to $400{ }^{\circ} \mathrm{C}$, the specimen exhibited a relatively smooth worn surface. Moreover, some narrow faint ploughing grooves can be seen, which is because the surface asperities of higher hardness that countered the GCr15 steel balls could microcut or plough the $37 \% \mathrm{C}_{\mathrm{f}} / \mathrm{LAS}$ composite surface. Meanwhile, a large amount of adherence straps occurred on the friction surface along the sliding direction for the $37 \% \mathrm{C}_{\mathrm{f}} / \mathrm{LAS}$ composites.

To better illustrate the wear mechanism of $37 \% \mathrm{C}_{\mathrm{f}} / \mathrm{LAS}$ composites measured at different temperatures, the microstructures of the counter ball and wear debris were investigated (Fig. 10). It can be seen that different furrows appeared on the surface of the material, but these were shallow because of the presence of

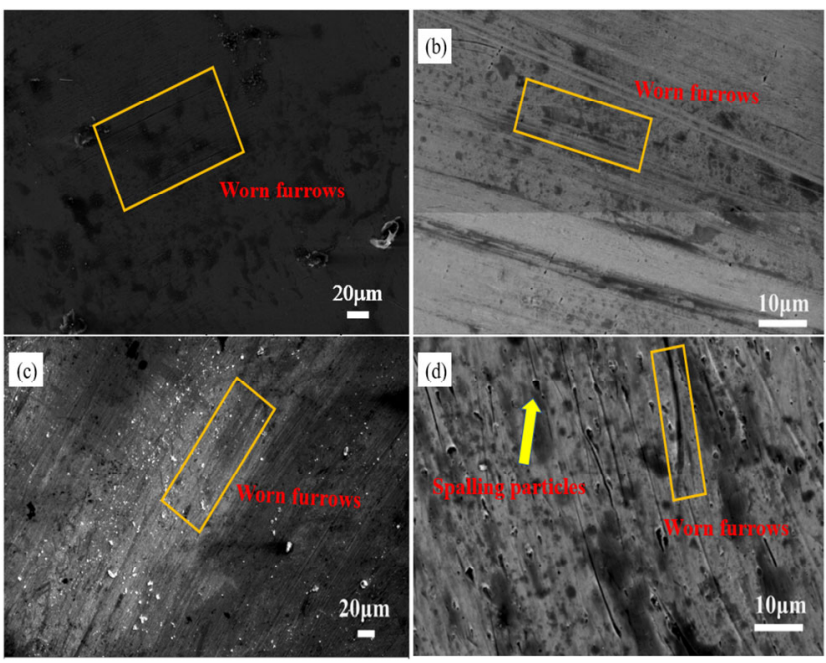

Fig. 10 Worn morphologies of the counter steel ball against $37 \%$ $\mathrm{C}_{\mathrm{f}} /$ LAS composites at different temperature: (a) room temperature, (b) $200{ }^{\circ} \mathrm{C}$, (c) $300{ }^{\circ} \mathrm{C}$, and (d) $400{ }^{\circ} \mathrm{C}$. 
microprotrusions on the surface of the glass-ceramic composite during the rubbing/sliding process. The hardness was also higher than that of the pair of grinding materials. When the two surfaces were sliding against each other, the microprotrusions formed a groove on the surface of the grinding ball. However, since the surface of the composite material forms a lamellar structure when friction is applied, it becomes smooth, and the proportion of microprotrusions is reduced; hence, the furrow depth to the surface of the grinding pair is shallow, and the number is not too large.

The morphologies of abrasive particles of $37 \% \mathrm{C}_{\mathrm{f}} / \mathrm{LAS}$ composites at different temperatures are shown in Fig. 11. The wear debris of $37 \% \mathrm{C}_{\mathrm{f}} / \mathrm{LAS}$ composites at room temperature, 200,300 , and $400{ }^{\circ} \mathrm{C}$ mainly consisted of hard particles and carbon fibers.

Visible and significant influences of temperature on the worn surface were observed. It can be seen from the figure that under the experimental conditions from room temperature to $400{ }^{\circ} \mathrm{C}$, there are broken carbon fibers in the wear debris. This means that during the rubbing process, some of the carbon fibers in the matrix were destroyed by the shearing force. In general, the abrasive grains are shaped like flakes. This is because these abrasive chips remained on the surface of the wear scar and appeared in the shape of sheet while being squeezed by the subsequent rubbing process.

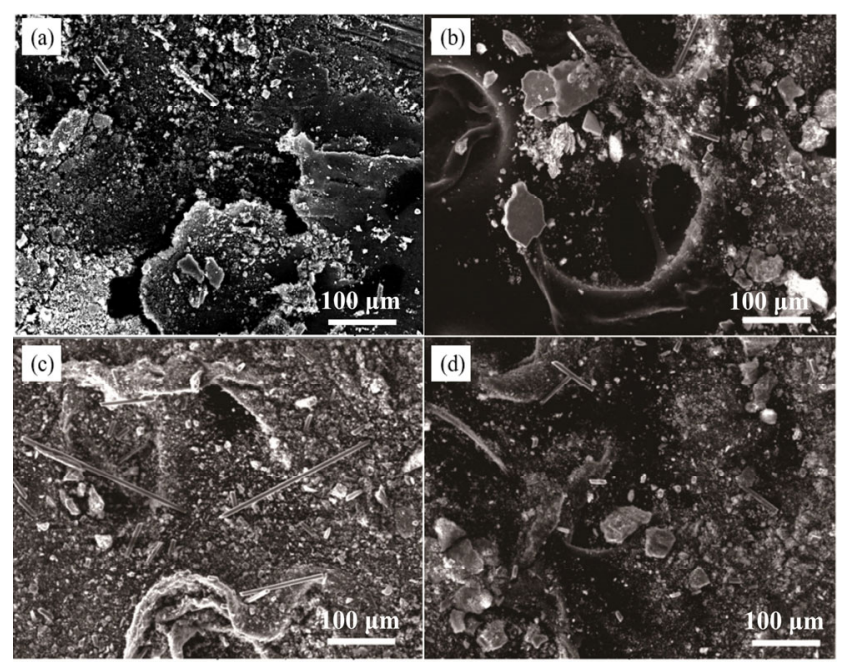

Fig. 11 Morphologies of worn debris during friction between $37 \% \mathrm{C}_{\mathrm{f}} / \mathrm{LAS}$ composites and the counter steel ball with sample temperature of (a) room temperature, (b) $200{ }^{\circ} \mathrm{C}$, (c) $300{ }^{\circ} \mathrm{C}$, and (d) $400{ }^{\circ} \mathrm{C}$.

\section{Conclusions}

Carbon-fiber-reinforced LAS matrix composites were prepared to investigate their mechanical properties and tribological behaviors under dry conditions. The effects of carbon fiber content of $0,33 \%, 37 \%$, $45 \%$ at room temperature, 200,300 , and $400{ }^{\circ} \mathrm{C}$ were investigated. The worn surface morphologies of these specimens were analyzed by SEM. The results show that the content and temperature of carbon fibers had a significant influence on mechanical and tribological properties under dry sliding conditions. The following conclusions can be drawn:

(1) The addition of carbon fibers significantly increased the flexural strength and fracture toughness compared with pure LAS glass-ceramics under dry conditions. The highest fracture toughness and flexural strength of $19.9 \pm 1.8 \mathrm{MPa} \cdot \mathrm{m}^{1 / 2}$ and $640 \pm 22 \mathrm{MPa}$, respectively, were achieved in $37 \% \mathrm{C}_{\mathrm{f}} / \mathrm{LAS}$ composites.

(2) Compared with LAS glass-ceramics, the $\mathrm{C}_{\mathrm{f}} / \mathrm{LAS}$ composite with steel-opposing materials had higher $\mathrm{COF}$ and lower wear rate. At room temperature, the $\mathrm{COF}$ and wear rates of $37 \% \mathrm{C}_{\mathrm{f}} / \mathrm{LAS}$ composites were $0.18 \times 10^{-6}$ and $2.04 \times 10^{-6} \mathrm{~mm}^{3} \cdot \mathrm{N}^{-1} \cdot \mathrm{m}^{-1}$, respectively. The types of wear of LAS glass-ceramics against GCr15 steel could be described as a combination of sliding wear and adhesive wear.

(3) When the sample temperature increased, both the $\mathrm{COF}$ and wear rate also increased. The COF greatly increased at $200-300{ }^{\circ} \mathrm{C}$, resulting in increased wear rate.

\section{Acknowledgements}

This work was supported by the National Natural Science Foundation of China (Grant Nos. 51621091, 51872058, 51772060, and 51972078) and Key Laboratory of Advanced Structural-Functional Integration Materials \& Green Manufacturing Technology, Harbin Institute of Technology, China.

Open Access This article is licensed under a Creative Commons Attribution 4.0 International Li-cense, which permits use, sharing, adaptation, distribution and reproduction in any medium or for-mat, as long as you give appropriate credit to the original author(s) 
and the source, provide a link to the Creative Commons licence, and indicate if changes were made.

The images or other third party material in this article are included in the article's Creative Commons licence, unless indicated otherwise in a credit line to the material. If material is not in-cluded in the article's Creative Commons licence and your intended use is not permitted by statutory regulation or exceeds the permitted use, you will need to obtain permission directly from the copyright holder.

To view a copy of this licence, visit http:// creativecommons.org/licenses/by/4.0/.

\section{References}

[1] Wright N A, Kukureka S N. Wear testing and measurement techniques for polymer composite gears. Wear 251(1-12): 1567-1578 (2001)

[2] Mao K. A new approach for polymer composite gear design. Wear 262(3-4): 432-441 (2007)

[3] Tunalioğlu M Ş, Tuç B. Theoretical and experimental investigation of wear in internal gears. Wear 309(1-2): 208-215 (2014)

[4] Fang Y, Fan H Z, Song J J, Zhang Y S, Hu L T. Surface engineering design of $\mathrm{Al}_{2} \mathrm{O}_{3} / \mathrm{Mo}$ self-lubricating structural ceramics-Part II: Continuous lubrication effects of a threedimensional lubricating layer at temperatures from 25 to $800{ }^{\circ} \mathrm{C}$. Wear 360-361: 97-103 (2016)

[5] Tatarko P, Kašiarová M, Chlup Z, Dusza J, Šajgalík P, Vávra I. Influence of rare-earth oxide additives and $\mathrm{SiC}$ nanoparticles on the wear behaviour of $\mathrm{Si}_{3} \mathrm{~N}_{4}$-based composites at temperatures up to $900{ }^{\circ} \mathrm{C}$. Wear 300(1-2): 155-162 (2013)

[6] Kim J H, Venkata M K B, Hong S H, Kim H D. Fabrication of silicon nitride nanoceramics and their tribological properties. $J$ Am Ceram Soc 93(5): 1461-1466 (2010)

[7] Wang C, Li K N, Chen H, Ma X M. Research progress of processing technology for fiber reinforced ceramic matrix composites. Aeronaut Manuf Technol (3): 55-60 (2016)

[8] $\mathrm{Hu}$ A M, Li M, Mao D L. Growth behavior, morphology and properties of lithium aluminosilicate glass ceramics with different amount of $\mathrm{CaO}, \mathrm{MgO}$ and $\mathrm{TiO}_{2}$ additive. Ceram Int 34(6): 1393-1397 (2008)

[9] Zocca A, Gomes C M, Bernardo E, Müller R, Günster J, Colombo P. LAS glass-ceramic scaffolds by three-dimensional printing. J Eur Ceram Soc 33(9): 1525-1533 (2013)

[10] Soares V O, Peitl O, Zanotto E D. New sintered $\mathrm{Li}_{2} \mathrm{O}$ $\mathrm{Al}_{2} \mathrm{O}_{3}-\mathrm{SiO}_{2}$ ultra-low expansion glass-ceramic. J Am Ceram Soc 96(4): 1143-1149 (2013)
[11] Dai N L, Luan H X, Liu Z J, Sheng Y B, Peng J G, Jiang Z W, Li H Q, Yang L Y, Li J Y. Broadband NIR luminescence of Bi-doped $\mathrm{Li}_{2} \mathrm{O}-\mathrm{Al}_{2} \mathrm{O}_{3}-\mathrm{SiO}_{2}$ glass-ceramics. J Non-Cryst Solids 358(22): 2970-2973 (2012)

[12] Beall G H, Pinckney L R. Nanophase glass-ceramics. J Am Ceram Soc 82(1): 5-16 (1999)

[13] Pelletant A, Reveron H, Chêvalier J, Fantozzi G, Blanchard L, Guinot F, Falzon F. Grain size dependence of pure $\beta$-eucryptite thermal expansion coefficient. Mater Lett 66(1): 68-71 (2012)

[14] García-Moreno O, Kriven W M, Moya J S, Torrecillas R. Alumina region of the lithium aluminosilicate system: a new window for temperature ultrastable materials design. $\mathrm{J} \mathrm{Am}$ Ceram Soc 96(7): 2039-2041 (2013)

[15] Chen J C, Huang G C, Hu C, Weng J P. Synthesis of negative-thermal-expansion $\mathrm{ZrW}_{2} \mathrm{O}_{8}$ substrates. Scr Mater 49(3): 261-266 (2003)

[16] Benavente R, Salvador M D, García-Moreno O, Peñaranda-Foix F L, Catalá-Civera J M, Borrell A. Microwave, spark plasma and conventional sintering to obtain controlled thermal expansion $\beta$-eucryptite materials. Int J Appl Ceram Tec 12(S2): E187-E193 (2015)

[17] Villalobos G R, Speyer R F. Electrical resistance as a tool in determining the failure of fibres in a nicalon-reinforced LAS glass-ceramic with $\mathrm{Ta}_{2} \mathrm{O}_{5}$ additions. J Mater Sci 32(21): 5577-5581(1997)

[18] Fox A G, Hunt R K, Maldia L C, Wang S W. Hot sodium sulphate corrosion of a Nicalon silicon carbide fibre-reinforced lithium aluminosilicate glass-ceramic matrix composite. J Mater Sci 30(24): 6161-6170 (1995)

[19] Drissi-Habti M. Assessment of the mechanical behaviour of $\mathrm{SiC}$ fibre reinforced magnesium lithium aluminosilicate glassceramic matrix composite tested under uniaxial tensile loading. J Eur Ceram Soc 17(1): 33-39 (1997)

[20] Kim K S, Jang H M, Baik Y K. SiC fibre-reinforced lithium aluminosilicate matrix composites fabricated by the Sol-Gel process. J Mater Sci 30(4): 1009-1017 (1995)

[21] Hasselman D P H, Donaldson K Y, Thomas JR J R, Brennan J J. Thermal conductivity of vapor-liquid-solid and vapor-solid silicon carbide whisker-reinforced lithium aluminosilicate glass-ceramic composites. J Am Ceram Soc 79(3): 742-748 (1996)

[22] Prewo K M, Brennan J J, Layden G K. Fiber reinforced glasses and glass-ceramics for high-performance applications. Am Ceram Soc Bull 65(2): 305-322 (1986)

[23] Phillips D C, Sambell R A J, Bowen D H. The mechanical properties of carbon fibre reinforced Pyrex glass. J Mater Sci 7(12): 1454-1464 (1972) 
[24] Sambell R A J, Bowen D H, Phillips D C. Carbon fibre composites with ceramic and glass matrices. J Mater Sci 7(6): 663-675 (1972)

[25] Phillips D C. Interfacial bonding and the toughness of carbon fibre reinforced glass and glass-ceramics. J Mater Sci 9(11): 1847-1854 (1974)

[26] Seghi S, Fabio B, Economy J. Carbon/carbon-boron nitride composites with improved wear resistance compared to carbon/carbon. Carbon 42(15): 3043-3048 (2004)

[27] Zhou X, Zhu D M, Xie Q, Luo F, Zhou W C. Friction and wear properties of C/C-SiC braking composites. Ceram Int 38(3): 2467-2473 (2012)

[28] Hyuga H, Jones M I, Hirao K, Yamauchi Y. Influence of carbon fibre content on the processing and tribological properties of silicon nitride/carbon fibre composites. J Eur Ceram Soc

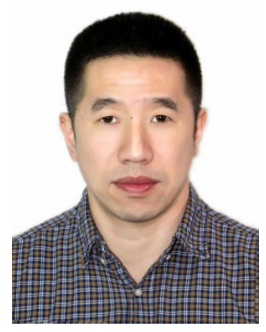

Long XIA. He received his M.S. degree in materials physics and chemistry from Lanzhou University in 2004 and Ph.D. degree in materials science from Harbin Institute of Technology in 2013. He joined the Department of Materials Science at
24(5): 877-885 (2004)

[29] Xia L, Zhao G L, Huang X X, Wen G W, Dai J Q, Zhao Z H. Effect of graphite intercalation compounds in the interfacial zone on the mechanical and thermal properties of unidirectional carbon fiber reinforced spodumene composite. Acta Mater 61(9): 3522-3532 (2013)

[30] Xia L, Wang X Y, Wen G W, Li X, Qin C L, Song L. Influence of brick pattern interface structure on mechanical properties of continuous carbon fiber reinforced lithium aluminosilicate glass-ceramics matrix composites. J Eur Ceram Soc 32(2): 409-418 (2012)

[31] Mazo M A, Tamayo A, Rubio J. Advanced silicon oxycarbidecarbon composites for high temperature resistant friction systems. J Eur Ceram Soc 36(10): 2443-2452 (2016)

Harbin Institute of Technology at Weihai from 2004. His current position is an associate professor and the deputy director of the Department of Materials Science. His research areas cover the tribology of ceramics matrix composites, interfacial phenomena and control of ceramics matrix composites. 